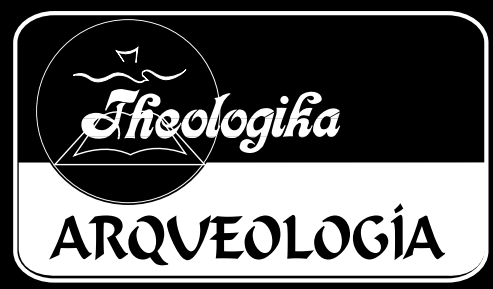

\title{
El santuario celestial en la apocalíptica qumránica
}




\section{Rodrigo P. Silva}

Centro Universitario Adventista São Paulo - Brasil 


\section{RESUMEN}

"El santuario celestial en la apocalíptica qumránica" - El autor estudia la temática del Santuario Celestial y el ministerio sacerdotal relacionado con él como se halla contenido en la apocalíptica del Qumrán. Así, la comunidad del Qumrán entendió que existe un templo divino en el cielo y que la restauración de las verdades divinas está directamente relacionada con él. De esta forma, se da evidencia que el tema del santuario y sus implicancias teológicas no fue una innovación doctrinal de los adventistas, en cambio, fue una realidad escriturística que aún los judíos de la antigüedad, no pertenecientes al círculo del cristianismo escrutaron y desarrollaron.

Palabras clave: apocalíptica, Qumrán, santuario celestial, judaísmo antiguo

\section{SUMMARY}

"The Heavenly Sanctuary in Qumranic Apocalyptic" - The author studies the theme of the heavenly sanctuary and the priestly ministry as is registered in the apocalyptic of Qumran. In this regard, the Qumran community understood that there is a divine temple in heaven and the restoration of its divine truths is directly related to it. Thus, evidence is given that the sanctuary motif and its theological implications were not a doctrinal innovation of Adventists, but it was a scriptural reality that even the Jews of antiquity not belonging to the currently Christian circle screened and developed.

Keywords: apocalyptic, Qumran, heavenly sanctuary, ancient Jewry 


\section{EL SANTUARIO CELESTIAL EN LA APOCALÍPTICA QUMRÁNICA}

\section{Introducción}

Apocalíptica es una palabra que ha causado mucho debate y ambigüedad. ${ }^{1}$ Generalmente, ha sido utilizada para designar una cosmovisión de la historia, un tipo específico de literatura o aún un movimiento social. Esto, sin mencionar los problemas que la semántica hizo surgir en los últimos tiempos, cuando apocalíptica (y sus congéneres, apocalíptico, apocalipsis, etc.) se asoció con los movimientos fanáticos aficionados al tema del "fin del mundo" y las "teorías conspirativas". En los años 70, Koch ya había hecho una distinción clásica entre "apocalipsis" y "apocalíptico", cosa que apalancó nuevas discusiones sobre un asunto que estaba medio dormido desde cuando Friedrich Lücke lanzó el término apocalíptico en 1852.

Apocalipsis, en esta nueva definición, sería un género literario, y apocalíptica cubriría un movimiento históricosocial. ${ }^{2}$ Para Koch, la discusión sobre la apocalíptica se

${ }^{1}$ Klaus Koch, Difficoltà dell'apocalittica: scritto polemico su d'un settore trascurato della scienza biblica (Brescia: Paideia Editrice, 1977).

${ }^{2}$ Klaus Koch, The Rediscovery of Apocalyptic: A Polemical Work On a Neglected Area of Biblical Studies and Its Damaging Effects On Theology and Philosophy, Studies in Biblical theology, 2da ser., vol. 22 (Naperville, Ill.: A. R. Allenson, 1972), 23. 
inicia con la propia definición sobre los libros que serían o no parte de este género. ${ }^{3}$

En 1975, Hanson perfeccionó este concepto dividiendo la apocalíptica en tres ramas: el apocalipsis, que serían los géneros literarios; el apocalipsismo, que sería un movimiento socioreligioso y la escatología apocalíptica que sería una perspectiva religiosa no limitada a los movimientos $\mathrm{o}$ a la literatura apocalíptica. ${ }^{4}$

Hoy la tendencia de los especialistas es mantener cada vez más claras las distinciones señaladas anteriormente, abandonando el uso de la apocalíptica como palabra inequívoca. Se percibe que ella comprende un conjunto de elementos literarios, teológicos y sociales, que se pueden encontrar incluso en materiales no necesariamente clasificados como apocalipsis. ${ }^{5}$

\section{${ }^{3}$ Ibíd.}

${ }^{4}$ P. D. Hanson, "Apocalypticism”, The Interpreter's Dictionary of the Bible: Supplementary Volume (Nashville: Abingdon, 1976), 27-34.

${ }^{5} \mathrm{El}$ foro de la SBL promovió en los años 70 uno de los debates sobre el género apocalíptico, organizado por J. J. Collins. Las discusiones dieron como resultado una excelente definición propuesta por el grupo y a pesar de que han pasado más de tres décadas, ella sigue siendo aceptada y utilizada como referencia por la mayoría de los especialistas: "Apocalipsis es un género literario de revelación con un marco narrativo, en el que una revelación está mediada por un ser externo a nuestro mundo para un recipiente humano, revelando una realidad trascendente que es a la vez temporal, en la medida en que vislumbra la salvación escatológica, especialmente en la medida en que ella envuelve otro mundo sobrenatural". Más adelante, por sugerencia de los biblistas Hellholm y Aune, se añadió esta nota a la definición anterior, la que es de especial interés para quienes tienen una visión historicista de la profecía: “[El Apocalipsis] trata de interpretar la actualidad, como las circunstancias terrenales, a la luz del mundo sobrenatural y del futuro e influir tanto en la comprensión y el comportamiento del público a través de la autoridad divina". John Joseph Collins, "Introduction: Towards the Morphology of a Genre", en Apocalypse: The Morphology of a Genre, ed. John Joseph Collins, Semeia 14 (Missoula, MT: Society of Biblical Literature, 
En el caso de Qumrán, predomina la idea de que era una comunidad apocalíptica que curiosamente no escribió libros apocalípticos. Esta idea es el resultado de la distinción ya señalada entre "apocalipsis" como categoría literaria y apocalíptica como un conjunto mayor de elementos y valores encontrados aun en otros géneros literarios. ${ }^{6}$

En efecto, la posición más ampliamente aceptada difiere de aquella representada por H. Stegemann en el famoso Congreso de Apocalíptica, realizado en 1979 en Uppsala. En aquella oportunidad, varios académicos, especialmente los pertenecientes a la escuela alemana, entendían que la comunidad de Qumrán no tenía ningún interés en el apocalipsismo y que sus manuscritos no contribuían en absoluto a la comprensión de este fenómeno o género literario. ${ }^{7}$ Empero, estudios posteriores publicados por J. J. Collins ${ }^{8}$ y F. G. Martínez ${ }^{9}$ contribuyeron grandemente para mostrar una íntima relación entre la comunidad del mar Muerto y la teo-

1979), 9. D. E. Aune, "The Apocalypse of John and the Problem of Genre" Semeia 36 (1986) 87 e David Hellholm, "The Problem of Apocalyptic Genre and the Apocalypse of John", Semeia 36 (1986) 13-64.

${ }^{6}$ P. D. Hanson, The Dawn of Apocalyptic, ed. rev. (Philadelphia: Fortress, 1979), 430-438; C. A. Newsom, "Apocalyptic and the Discourse of the Qumrán Community", Journal of Near Eastern Studies 49 (1990) 135-144.

7F. G. Martinez, "Apocalypsism in Dead Sea Scrolls", en The Continuum History of Apocalypticism, eds. B. McGinn, J. J. Collins e Stephen Stein (New York: Continuum, 2003), 90.

8J. J. Collins, "Was the Dead Sea Sect an Apocalyptic Movement?", en Archaeology and History in the Dead Sea Scrolls, ed. Lawrence H. Schiffman (Sheffield: JSOT, 1990), 25-51.

${ }^{9}$ Martínez, 91, 92. 
logía apocalíptica que marcó los movimientos judaicos del I siglo de nuestra era. ${ }^{10}$

Sin embargo, tal reconocimiento no es de ayuda para hacer en el corpus de Qumrán un checklist exacto de lo que haría o no parte del material estrictamente apocalíptico, especialmente en relación con los textos arameos. ${ }^{11}$ Por supuesto, un libro como el Rollo de la Guerra, que presenta la lucha de los hijos de las tinieblas contra los hijos de la luz, tiene un contenido apocalíptico inequívoco; pero pasar de esta observación a clasificarlo como un apocalipsis es otra cosa, que ni los más destacados académicos están dispuestos a hacerlo. ${ }^{12}$ Incluso J. J. Collins, que como se dijo, fue un pionero en la identificación del Qumrán como una comunidad apocalíptica, admitió que debido a la actual

\footnotetext{
${ }^{10}$ Hasta los editores del CD admiten eso, sin embargo algunas voces aisladas todavía niegan la relación entre el Qumrán y el apocalipticismo de la ocasión. Es el caso, p. ej. de P. R. Davies, "Qumran and Apocalyptic or Obscurum per Obscurius", Journal of Near Eastern Studies 49:2 (1990) 127-34.

${ }^{11}$ En 1992 Martínez publicó como editor una serie de siete artículos sobre los documentos arameos de Qumrán y su conección con los apocalipsis. La principal tesis de los ensayos ya aparece en la introducción donde Martínez afirma que los manuscritos de Qumrán y los apocalipsis se iluminan uno al otro. F. G. Martínez [ed.], Qumran and Apocalyptic: Studies on the Aramaic Texts from Qumran [Studies on the Texts of the Desert of Judah, 9] (Leiden: Brill, 1992).

${ }^{12}$ D. Flusser, "Apocalyptic Elements in the War Scroll", vol. 1 de Judaism of the Second Temple Period - Qumran and Apocalypsism (Co edição: Grand Rapids, MI: Cambridge, Jerusalem: Wm. B. Eerdmans, Magnes Press, Jerusalem Perspective, 2007), 140; C. Rowland, The Open Heaven: A Srudy of Apocalyptic in Judaism and Early Christianity (London: SPCK, 1982), 42; J. J. Collins, Apocalypsismn in Dead Sea Scrolls (London: Routledge, 1997), 10; P. R. Davies, "Qumran and Apocalyptic or Obscurum per Obscurius", 133.
} 
concepción del género apocalíptico no se puede decir que Qumrán haya producido un libro que deba llevar ese nombre. ${ }^{13}$

Aun Dimant, en su intento pionero por clasificar temáticamente el cuerpo arameo de los manuscritos, evitó la categoría "apocalipsis" y prefirió hablar más genéricamente de "composiciones visionarias". ${ }^{14}$ Además, se tiene el problema de la amplia variedad de ideas relativas sobre revelación y escatología que se encuentran en los manuscritos y el no saber con certeza qué textos fueron producidos originalmente por la comunidad o cuáles fueron solo copiados y preservados por ella. En este sentido, escapa al alcance de esta investigación el discutir qué materiales son o no originalmente Qumránicos. ${ }^{15}$ Nuestro objetivo apenas es verificar en qué medida las antiguas interpretaciones del judaísmo se relacionan o no con lo que hoy llamamos la doctrina del santuario.

Por lo tanto, la temática del santuario celestial, que será el tema de este artículo, no surge necesariamente de un género literario contenido en la Biblioteca de Qumrán, sino del espíritu apocalíptico que moldeó la ideología manifestada en varios documentos allí encontrados, sean o no producidos por la comunidad.

${ }^{13} \mathrm{~J} . \mathrm{J}$. Collins, The Apocalyptic Imagination in Ancient Judaism (New York: Crossroad, 1984), 140, 206.

${ }^{14} \mathrm{D}$. Dimant, "The Qumran Aramaic Texts and the Qumrán Community", en Flores Florentino. Dead Sea Scrolls and Other Early Jewish Studies in Honour of Florentino García Martinez, ed. A. Hilhorst, E. Puech and E. Tigchelaar; JSJSup 122 (Leiden Brill, 2007), 197-205.

${ }^{15}$ Para una visión general sobre este problema véase C. Newsom "'Sectually Explicit' Literature from Qumran," en The Hebrew Bible and Its Interpreters, eds. W. H. Propp, B. Halpern and D. N. Freedman (Winona Lake, IN: Eisenbrauns, 1990), 167-187. 
Semejantes orientaciones apocalípticas también caracterizan el kerigma de la iglesia cristiana primitiva, que, al igual que la comunidad del desierto, creía poseer una revelación especial de Dios, una visión mesiánica del tiempo, una expectativa escatológica del futuro y una concepción determinista de la historia dividida en periodos proféticos.

También es importante aseverar que la "semejanza" entre los movimientos cristianos y el qumránico no significa la "transferencia" exacta de uno sobre otro, ni mucho menos una dependencia teológica entre ambos. Todo intento por visualizar el Qumrán como "fuente" del cristianismo primitivo se mostró infructífero. Lo que se puede ver es una semejanza, probablemente originada por el simple hecho de que ambos movimientos se inspiraron en el mismo conjunto autoritativo de textos, a saber, las Sagradas Escrituras del judaísmo. En este sentido, los manuscritos del Qumrán nos ayudan a ver cómo pensaban algunas de las diversas corrientes judaicas que existían en el periodo del Segundo Templo. De este modo, ellos también pueden brindar luz sobre el contexto judaico de los cristianos primitivos.

Se hace necesaria una última acotación sobre la relevancia de esta investigación para la teología adventista. No se trata de buscar en Qumrán los orígenes de la doctrina adventista del santuario. Su fundamentación es esencialmente bíblica. Sin embargo, el hecho de encontrar una antigua interpretación del judaísmo que, leyendo las Escrituras en su propio idioma, descubrió, distinta e independientemente del adventismo moderno, la existencia de un santuario celestial y un ministerio sacerdotal relacionado con él, es algo realmente muy interesante. 
No se trata de una cuestión de mera curiosidad arqueológica, ni mucho menos de un intento artificial de forzar correspondencias entre el Qumrán y los Adventistas del Séptimo Día. Hay claras distinciones entre los dos movimientos y muchas lagunas en relación a la comprensión teológica del más antiguó. El presente trabajo no ignora esto. El objetivo, pues, de este estudio es evidenciar que el descubrimiento de los pioneros acerca del santuario y sus implicancias teológicas no fue una innovación doctrinal jamás imaginada en el judaísmo antiguo. Por lo contrario, fue una realidad escriturística que aun judíos de la antigüedad, no pertenecientes al círculo del cristianismo, se percataron de él y lo reprodujeron en su teología.

\section{Trasfondo escriturístico}

Varios textos del Antiguo Testamento (AT) describen a Dios habitando un monte sagrado (Sal 3:4, 24:3; 68:16; 87:1-3; Isa 2:2,3; Amós 4:13; Joel 3:17,21). Entre ellos se destaca el Salmos 15:1, donde la expresión "tu Monte Santo" (běhar qodšekā) es paralela a "tu tabernáculo" o "tu tienda"

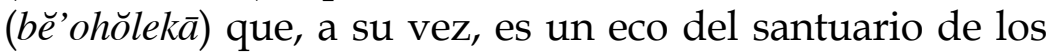
hebreos (Num 9.15; 17:22,23 etc.). En la cultura cananea 'E $\bar{l} l$ también es descrito de modo intercambiable como habitando en un monte o en un tabernáculo - lo que corrobora el hecho de que existe correspondencia entre tem$\mathrm{plo/monte/santuario} \mathrm{y} \mathrm{tabernáculo} \mathrm{como} \mathrm{algo} \mathrm{común} \mathrm{en}$ la cultura del antiguo Oriente Medio. ${ }^{16}$ En este sentido,

${ }^{16} \mathrm{R}$. J. Clifford, “The Tent of El and the Israelite Tent of Meeting” en Catholic Biblical Quarterly 33 (1971) 221-27; idem, The Cosmic Mountain in Canaan and the Old Testament, Harvard Semitic Monographs IV (Cambridge: Harvard University Press, 1972), 34-176; E. Theodore Mullen, The Divine 
como lo afirma Andreasen, "Cuando consideramos el entendimiento del Antiguo Oriente Medio sobre la relación entre el cielo y la tierra, se debe estar alerta al hecho de que el AT también puede adoptar, modificar o rechazar completamente tales entendimientos. En el mejor de los casos, pueden lanzar luz sobre el $\mathrm{AT}^{\prime \prime} \cdot{ }^{17}$

Muchos hebraístas creen que el título divino šadday (en algunos casos ' $\bar{E} l$ šadday), aplicado más de 40 veces a Dios en el AT, puede venir del vocablo acadio šadu que quiere decir "montaña". Así la traducción para 'E $\bar{l}$ šadday sería "Dios de la montaña", es decir, Dios que habita en la montaña. ${ }^{18}$

Tal descripción, hasta cierto punto, es intrigante. La cultura del Antiguo Oriente Medio, al igual que la Biblia, también describe a ciertas divinidades locales como habitando las montañas, un ejemplo es el caso de ' $\bar{E} l .{ }^{19}$ Igualmente, en la mitología ugarítica, Baal tenía un palacio muy alto sobre el monte Zaphon y Anat, y es descrita como la diosa que mora en la montaña de 'Inbubu.

Council in Canaanite and Early Hebrew Literature, Harvard Semitic Monographs, 24 (Missoula, Montana: Scholars Press, 1980), 128-174; J. Day, Yahweh and the Gods and Goddesses of Canaan. Journal for the Society of the Old Testament Supplement Series 265. (Sheffield: Sheffield Academic Press., 2000), 30, 31.

${ }^{17}$ N. E. Andreasen, "The Heavenly Sanctuary in the Old Testament", en The Sanctuary and the Atonement - Biblical, Historical, and Theological Studies, eds. A. V. Wallenkampf e W. R. Lesher (Washington D.C., Review and Herald, 1981), 67.

${ }^{18}$ F. M. Cross, "Yahweh and the God of the Patriarchs", Harvard Theological Review, 55 (1962), 246; W. F. Albright, "The Names Shaddai and Abram", Journal of Biblical Literature 54 (1935) 173-193.

${ }^{19}$ R. J. Clifford, Cosmic Mountain in Canaan and the Old Testament (Cambridge, MA: Harvard University Press, 1972), 9-97. 
Existen algunas semejanzas aquí. La Biblia no describe al Señor de manera estática, restringido a una sóla montaña. Él por lo contrario, se mueve de montaña en montaña y desciende para hablar con su pueblo que está en la planicie. Varios pasajes describen al Dios de los hebreos en constante marcha, rodeado por huestes angélicas, viniendo poderosamente desde su santo monte. Dice Deuteronomio 33:2 "Jehová vino de Sinaí, y de Seir les esclareció; resplandeció desde el monte de Parán, y vino de entre diez millares de santos, con la ley de fuego a su mano derecha". Una descripción similar puede ser vista en Jueces 5:4-5; Salmo 68:8,9 y Habacuc 3:3.

Asimismo, esa habitación divina, a pesar de ser real, no significa un confinamiento absoluto del Altísimo. Ni el cielo, ni la tierra, ni un santuario podrían contenerlo (1 Rey 8:27, cf. También 2 Cro 6:18; Sal 139:7-10 y Hechos 17:24). Al mismo tiempo que la Biblia lo presenta morando en la Tierra (Exo 25:8; Jer 3:17) también lo describe habitando el cielo (Deu 26:15; Sal 103:19; 123:1) y el corazón de aquellos que lo aman (Isa 57:15).

Es necesario notar que, aun cuando divinidades paganas también puedan ser representadas como habitando en montañas, santuarios o tiendas, estos jamás tienen por objetivo promover la comunión personal entre Dios y su pueblo. Sino que, por lo contrario, se trata de un aislamiento. El monte en el que Baal moraba, se encuentra a por lo menos $40 \mathrm{Km}$ de Ugarit, en el mito hitita/cananita de Elkunirša, 'él el dios creador vive en una tienda igualmente distante localizada sobre una montaña en la ribera del rio Mala que es el Éufrates. ${ }^{20}$ El Dios de la Biblia, diferente

${ }^{20}$ Hoy sabemos que el Eufrates nace en las montañas orientales de 
a todo eso, se mueve de montaña en montaña siguiendo a su pueblo y más; Él establece para si una tienda entre otras tiendas humanas, en medio del campamento hebreo (Exo 25:8, 1 Rey 6:12-13). Es por eso que el santuario del desierto también era denominado "tienda de reunión" o "tabernáculo de reunión" ('ō'hěl mô ‘éd ', Exo 40:32) un nombre jamás aplicado a los santuarios paganos.

Por lo menos, tres montañas son directamente designadas como habitación temporal de Dios, entre las cuales Él se mueve: Sinaí, Horeb y Sion. Estas y otras elevaciones montañosas son también relacionadas simbólicamente al cielo y al tabernáculo celestial, igualmente llamado "morada del Señor" (Sal 123:1; Ecle 5:2; Sal 102:1,19).

En este sentido, se debe tener en cuenta que las expresiones "cielo" y "santuario celestial" no parecen sinónimos perfectos. A pesar de que tiene estrecha relación entre si, el santuario celestial no es el cielo mismo, sino un ambiente fundamentado en aquel lugar. Salmo 78:69 presenta a Dios construyendo un santuario duradero como el cielo (es decir, una parte de ello) y tan firme como la tierra, algo tan real, auténtico y distintivo en el universo como el planeta en que vivimos.

Los primeros capítulos del Génesis no dicen nada sobre montañas y santuarios como la morada de Dios. Sin embargo, el libro de Ezequiel hace una alusión poética al Edén, retratándolo como un jardín situado sobre una mon-

Turquia, con todo, autores como J. Day suponen mas no dogmatizan que la referencia textual sería a una montaña da Armenia. E. Lepiński, a su vez, utilizando otros textos ugaríticos aboga por el monte Hermón como morada de El. Cf. Edward Lipinski's “El's Abode: Mythological Traditions Related to Mount Hermon and to the Mountains of Armenia", Orientalia. Lovaniensa Periodica II (1971) 13-69; J. Day, 31. 
taña, la montaña donde mora Dios (Eze 28:13, 14:16). Y no se puede olvidar la relación antes mencionada entre la montaña y el santuario. G. K. Beagle observa que así como el Templo de Israel debía construirse sobre un monte con su entrada mirando hacia el Este (Exo 15:17) y así como el Templo escatológico de Ezequiel también se construiría en una colina con vista hacia el oriente (Eze 40:2, 6; 43:12), del mismo modo, el Edén, como un verdadero santuario de Dios, se encuentra en una montaña afirmada hacia el oriente (Eze 28:14, 16; Gen 3:24). ${ }^{21}$

La misma raíz verbal mithallek, usada para describir a Dios andando por el jardín a plena luz del Día (Gen 3:8) describe la presencia divina en el Santuario de los hebreos (Lev. 26:11, 12; Deu 23:14[15]; 2 Sam 7:6-7). De hecho, como afirma Davidson, ${ }^{22}$ el lenguaje usado en el Génesis para describir la ocupación de Adán y Eva claramente alude al santuario y al trabajo de los sacerdotes y levitas. De este modo, no es erróneo entender al santuario del Edén como un tipo del santuario celestial (Exo 25:9,40), aunque esto no niega su realidad literal en el cielo.

Que la comunidad del Qumrán también vio al Edén como una especie de santuario celestial en la tierra, es evidente por la forma paradigmática como 4Q265 72 11-17 presenta el ritual de purificación al cual Adán y Eva supuestamente se tuvieron que someter antes que pudiesen tener su primer acceso al jardín. El Edén, en este contexto,

${ }^{21} \mathrm{G}$. K. Beale, The Temple and the Church's Mission: A biblical theology of the dwelling place of God (Downers Grove, IL InterVarsity Press, 2004), 66; cf. también idem, "Eden, the Temple and the Church's Mission in the New Creation", Journal of the Evangelical Theological Society 48:1 (2005).

${ }^{22}$ Richard M. Davidson, "Cosmic Metanarrative for the Coming Millennium", Journal of Adventist Society 11 (2000) 108-111. 
es tratado como el lugar santísimo, la presencia de Dios y la preparación de adán y Eva se torna en un símil de la preparación del sumo sacerdote en el día de la expiación. ${ }^{23}$

Note que, de forma curiosa, Génesis 3:24 describe la expulsión del jardín afirmada por la presencia de querubines (posiblemente dos) que cuidaban el camino hacia el árbol de la vida. En otras partes de la Biblia, estos seres hacen parte de la descripción gloriosa del trono de Dios (Exo 9:3, 10:4; Sal 99:1). En medio de los querubines del Edén, una espada de fuego se movía, brillando como la letal shekinah de la presencia de Dios (Exo 25:22, Isa 37:16). ${ }^{24}$

De este modo, la idea del santuario/montaña sagrada, prepara al lector para todas las otras, significativas montañas de la historia de la redención. Estás, por su lado, se convierten en un arquetipo del templo de Dios que está en el cielo. El ejemplo clásico es el Sinaí. Se le ordenó a Moisés construir un tabernáculo (miškān') y todo su mobiliario de acuerdo con el "modelo" (mišpạt' o tabnit) que él vio -ciertamente es una visión ( $\mathrm{ra}^{\prime} \mathrm{ah}$ ) - en el monte (Exo 26:30: cf. Exo 25:9, 40; 27:8 y Num 8:4). El tabernáculo levantado en el desierto era, por lo tanto, una copia exacta de otra tienda vista en la montaña, en concordancia con el principio religioso del "tal cual". Aun cuando sea claro que, de acuerdo a Hebreos 8:2-5, este santuario terrenal

${ }^{23}$ Que el santuario celestial ya existía antes del pecado se torna claro por textos como Jeremías 17:2; Ezequiel 28 e Isaías 14.

${ }^{24}$ Seventh-day Adventist Bible Commentary, vol I (Washington D.C.: Review and Herald, 1978), 236. El libro de los jubileos 3:14 (4Q 217 ou 4QJub $^{b}$ ) tiene una interpretación semejante al explicar las leyes levíticas: el también trata al Edén como el santuario de Dios y eso se torna todavía más explícito en el trecho de 8:19 que dice: "Y él [Noé] sabía que el jardín del Edén era el Santo de los Santos, la morada del Señor". 
era apenas una "sombra" del "verdadero tabernáculo que erigió Dios y no el hombre".

La similitud entre la forma del habitáculo terrenal de Dios y su prototipo celestial pone de manifiesto la verdadera presencia del Señor, que apunta a una realidad literal y no simbólica de otro santuario que se encuentra en los cielos. $^{25}$

Cuando Moisés deja el pueblo a los pies del monte, lleva con él setenta ancianos y algunos sacerdotes y sube a la montaña. El primer grupo está más abajo, el segundo sube parte de la ruta y solo Moisés entra en la nube de la gloria de Dios (Exo 24:12-18). Esto se convierte en un preludio de la triple división del tabernáculo y del templo, que se dividen en el patio, santo y santísimo. En esta última habitación se guardaban los mandamientos y allí también, en medio de la nube, se manifestaba la presencia del Señor.

Isaías 6 esboza el llamado del profeta como llevándose a cabo en el santuario celestial. Allí el autor bíblico presenta una estructura donde el santuario terrenal y celestial se unen para un solo objetivo, así como el sacerdocio y la tradición mesiánica profética. Siguiendo el argumento textual, la presuposición básica de Isaías es que Dios está sentado en su santuario del cielo, rodeado de ángeles y gloria. También el mismo humo que se eleva desde el templo de Jerusalén llena el templo celestial, lo que le permite percibir la impureza humana y la necesidad de expiación. Según Isaías 6, la obra terrenal del sacerdote tiene continuidad en el templo celestial.

${ }^{25}$ F. B. Holbrook, "The Israelite Sanctuary", en The Sanctuary and the Atonement - Biblical, Historical, and Theological Studies, eds. A. V. Wallenkampf e W. R. Lesher (Washington D. C., Review and Herald, 1981), 4 y 5. 
No solamente eso, la liturgia también expresa esa realidad. Cuando el pueblo cantaba "santo, santo, santo es el Señor de los ejércitos", se hacía eco en la tierra, al coro celestial que unía su voz en unísono con una multitud de adoradores. ${ }^{26}$ Note que el Salmo 22:3 dice que el Señor "habita entre las alabanzas de Israel", pero al mismo tiempo el Salmo 99:1 dice que "Él está sentado sobre los querubines". ${ }^{27}$

\section{Qumrán}

¿Cómo, por fin, los escritos de Qumrán hablaron sobre esa realidad bíblica? A pesar de las muchas discusiones sobre la teología de la comunidad (y si, de hecho se trataba de una comunidad), la centralidad temática del templo y del "fin de los días" (aharitha-yamim) fue siempre perceptible en estos manuscritos. ${ }^{28}$

Tomemos por ejemplo, el Documento de Damasco (CD-

${ }^{26} \mathrm{~J}$. Levenson, "The Jerusalem Temple in Devotional and Visionary Experience" en Jewish Spirituality, ed. A Green, vol. 1 (London: SCM, 1989), 32-61.

${ }^{27}$ Los escritos de Levi Aramaico y los Jubileos (también preservados fuera de Qumrán) presentan un ministerio sacerdotal en unísono con los ángeles. "Tu [Sacerdote Levita] estás cerca de Dios y de todos sus santos" (Levi Aramaico 6:5). De igual modo, los Jubileos 31:14 también dice: [el sacerdote levita] "sirve en su templo [i.e. del Señor] del mismo modo como los ángeles de la presencia y del mismo modo que los santos [del cielo]".

${ }^{28} \mathrm{~A}$ pesar de una aparente diversidad en la expectativa escatológica encontrada en los Manuscritos de Qumrán, Davies (sigue negando las relaciones entre Qumrán y el apocaliptisismo de la época) admitió la centralidad de estos temas propuestos y la gran parte de los académicos sigue en esta misma dirección. Cf. P. R. Davies, "Eschatology at Qumran" Journal of Biblical Literature 104 (1985) 54, 61-78; idem, The Damascus covenant: an interpretation of the "Damascus document" (Sheffield: Sheffield Academic Press, 1983), 56-104. 
A) y el Rollo del Templo (11QTa). En el primero se habla de Dios, como construyendo una casa "tal cual nunca hubo desde los tiempos antiguos hasta ahora" (CD-A III 19). El texto continúa ofreciendo una interpretación escatológica de Ezequiel 44: 15 donde se menciona el servicio del templo (CD-A III 19 - IV 4a).

En el otro texto, el 11QTa 29. 1-10, hay la mención de otro templo especial, en ambos textos, puede ser interpretado como un "Templo escatológico" ${ }^{29}$

$[Y]$ "sus libaciones [...] Estos son [...] para vuestros holocaustos y vuestras libaciones [...] En la casa sobre la cual haré morar mi nombre [ofrecerán] los holocaustos, [cada día que corresponde] a ese día, según la instrucción de este precepto, continuamente, de la parte de los hijos de Israel, más allá de sus ofrendas voluntarias. Todo lo que me ofrecerán, todas sus libaciones y todos los regalos que me traigan para ser aceptados, los aceptaré. Ellos serán para mí un pueblo, y yo seré para ellos siempre y los estableceré para siempre. Santificaré mi templo con mi gloria, pues haré morar sobre el mi gloria hasta el día de la creación, cuando cree mi templo estableciéndolo para mí para siempre, de acuerdo a la alianza que hice con Jacob en Betel".

La mayor parte de autores sigue la misma línea de interpretación original de Yadin que ve aquí dos templos: uno provisorio (que podría ser la propia comunidad) y otro su-

${ }^{29}$ Véase por ejemplo J. L. Wentling, “Unraveling the Relationship between 11QT, the Eschatological Temple, and the Qumran Community" Revue de Qumran 14 (1989) 61-74. J. I. Kampen "The Significance of the Temple in the Manuscripts of the Damascus Document" en The Dead Sea Scrolls at Fifty: Proceedings of the 1997 Society of Biblical Literature Qumran Section Meetings, Early Judaism and Its Literature 15, eds. R. A. Kugler y E. M. Schuller (Atlanta, Ga.: Society of Biblical Literature, 1999), 185-197. 
perior, escatológico que se identifica con la Nueva Jerusalén mencionada en Isaías y en el Apocalipsis de Juan. ${ }^{30}$

Desde la publicación de la colección completa de los manuscritos en los años 90, las ideas sobre la relación entre los miembros de la comunidad y el Templo de Jerusalén ha sido modificada. Lo que se nota es que no había un direccionamiento único en ese sentido, o sea, el movimiento qumránico al igual que el judaísmo que lo rodeaba, manifestaba una pluralidad de convicciones. Pero a pesar de todo, ciertas directrices parecen más o menos uniformes en el pensamiento del pueblo. Entre ellas está la certeza de la existencia de un diferente templo o santuario localizado en el cielo, que está íntimamente asociado a las profecías del "tiempo del fin".

G. J. Brooke hizo una exhaustiva investigación sobre el rol y significado de estos templos en los rollos del mar Muerto, tratando de explicar la tensión entre el actual Templo de Jerusalén y el templo escatológico que teóricamente los autores idealizaron. ${ }^{31}$ En esta búsqueda él se enfrentó a diferentes descripciones del santuario, expuestas en los manuscritos. Los residentes de la comunidad, habían estudiado el Antiguo Testamento y encontraron allí diez diferentes tipos de templos -algunos de los cuales nos son familiares, como el templo de Salomón y Herodes, entre otros.

En la comprensión de Brooke, esos diez templos

${ }^{30} \mathrm{~F}$. García Martínez, “L'interprétation de la Torah d'Ezéchiel dans les MSS de Qumran", Revue de Qumrán 13 (1988) 441-452. Mas B. Z. Wacholder defiende que solo existe un templo en este texto y que sería el templo escatológico. Cf. Dawn of Qumran (Cincinati, OH: HUCA Press, 1983), 22-30.

${ }^{31} \mathrm{G}$. J. Brooke, "The Ten Temples in the Dead Sea Scrolls", en Temple and Worship in Biblical Israel, ed. J. Day (London: T \& T Clark, 2005), 417-434. 
pueden ser reducidos a tres categorías principales: La comunidad (como templo provisorio hasta la llegada del templo escatológico, la Nueva Jerusalén), el templo terrestre (localizado en Jerusalén) y el templo superior (localizado en el cielo).

No existe en los textos la expresión exacta "santuario celestial", como aquella comúnmente usada por los adventistas. Realmente tal expresión tampoco aparece en la Biblia, sin embargo, su concepto está allí bien definido, al igual que en los manuscritos del mar muerto. Esto, sin contar el uso de expresiones análogas como "santuario de eternidades" (Le miqdâsh 'ôlamim) que aparece en 4Q511 35.3 - 5 y "santuario del santo" (miqdâsh qodsho) que aparece en 4Q403 1 I 11 e 1 I 42. El texto además parece referirse al santuario celestial en la frase mishkan rosh rum kevod malkhuto devir "El más alto y exaltado tabernáculo, la gloria de su reino, el interior de su santuario" (4Q403 1 II 10). Otra posibilidad sería traducir "interior de su santuario" como "lugar santísimo", es decir, el segundo compartimiento del tabernáculo, el lugar de la presencia viva de Dios. ${ }^{32}$

\section{Ministerio sacerdotal en el cielo}

Qumrán poseyó además una elaborada liturgia, en la cual figuras angélicas participan de una especie de ministerio sacerdotal llevado a cabo en el cielo. ${ }^{33} \mathrm{El}$ manuscrito

${ }^{32} \mathrm{~W}$. Gesenius, Gesenius's Hebrew and Chaldee Lexicon to the Old Testament Scriptures (Grand Rapids, MI: Eerdmans, 1950).

${ }^{33} \mathrm{Cf}$, J. Strugnell, "The Angelic Liturgy at Qumran - 4QSerek Sirot 'Olat Hassabat', Suplements to Vetus Testamentum 7 (1959) 318-345. 
Cánticos del Sacrificio del Sábado (Serek Sirot 'Olat Hassabbat), también conocido como "Liturgia Angelical", es un documento de las primeras etapas del desenvolvimiento de la teología de Qumrán que nos trae esta información.

Diez copias fueron localizadas, ocho estaban en la gruta 4 (llamadas inicialmente 4 QShrirShab abcetc, y después 4 Q400 a 4Q407) una en la gruta 11 y otra en la fortaleza de Masada (Mas 1k). Su datación fue estimada entre el final del período hasmoneo y mediados del período herodiano (ca. 75 - 4 a.C.). ${ }^{34}$ La principal traducción y análisis de este documento se lo debe al trabajo de Carol Newsom, publicado en $1985 .{ }^{35}$

En resumen, se trata de una composición litúrgica formada por trece diferentes secciones, una para cada uno de los trece primeros sábados del año, probablemente solar. Las letras evocan el loor de los ángeles y su función sacerdotal en el santuario del cielo, así como la adoración del sábado en aquel santo lugar.

Es difícil saber si los himnos tenían una función litúrgica real o si apenas eran, como lo declara Newsom, un vehículo para la experiencia mística. ${ }^{36} \mathrm{O}$ aun ambas cosas,

${ }^{34}$ Smith sugiere una fecha anterior a la fundación de la comunidad y que puede ser retraída hasta el siglo III a. C. Cf. B. D. Smith, The Tension Between God As Reighteous Judge And As Merciful in Early Judaism (Lanham, ML: University Press of America, 2005), 31.

${ }^{35}$ C. Newsom, Songs of the Sabbath Sacrifice: A Critical Edition. (HSS 27; Atlanta: Scholars Press, 1985). Newsom continuó el trabajo incompleto de su profesor J. Strugnell que lanzó una versión también preliminar del texto con comentarios en 1960.

${ }^{36}$ C. A. Newsom et al., eds., "Angelic Liturgy: Songs of the Sabbath Sacrifice (4Q400 - 4Q407, 1 1Q17, Mas lk)", en The Dead Sea Scrolls: Hebrew Aramaic, and Greedk Texts with English Translations (Louisville: Westminster John Knox, 1999), vol. 4B, 138-189. 
como propuso Rietz. ${ }^{37}$ ¿Será que estos cánticos eran recitados públicamente los sábados para acompañar algún tipo de sacrificio terrenal conforme a la prescripción de Números 28:9-10?

Surge otra pregunta: ¿será que el ciclo de 13 liturgias sabáticas era repetido cuatro veces para ser mantenido a lo largo del año ( 4 × $13=52$ semanas $)$ ? O solo se refería al primer trimestre de un año de 364 días? ${ }^{38}$ Saber ello es difícil. Lo que se puede afirmar es que el sentimiento de coparticipación junto a la hueste celestial era evidente. El manuscrito, Regla de la Comunidad (I QS XI 7-8), afirma que los que participaban de la alianza son los escogidos de Dios para unirse con la asamblea de los hijos del cielo en la fundación de la casa de santidad -ciertamente el santuario celestial.

Pero lo que más llama la atención en un primer momento es ese ministerio sacerdotal de los ángeles. Dice el 4Q400 1 I 3 4: "porque [estableció] a los más santos de los santos entre los santos eternos, para que sean sacerdotes para él que se aproximen al templo de su realeza los servidores de la presencia en lo santísimo [devir] de su gloria".

${ }^{37} \mathrm{H}$. W. M. Rietz, "Identifying Compositions and Traditions of the Qumran Community" en Qumran studies: New approaches, New questions, eds., Michael Thomas Davis y Brent A. Strawn (Grand Rapids, Mich.: William B. Eerdmans, 2007), 43.

${ }^{38}$ Sobre el calendario de Qumrán de 364 días véase J. Ben-Dov “The 364-day Year in the Dead Sea Scrolls and Jewish Pseudepigrapha", en Calendars and Years II, ed. John Steele (Oxford/Oakville: Oxbow, 2011), 69105; J. C. Vanderkam, Calendars in the Dead Sea Scrolls: Measuring Time (London and New York;: Routledge, 1998); Uwe Glessmer, "Calendars in the Qumran Scrolls", en The Dead Sea Scrolls after Fifty Years: A Comprehensive Assessment, eds. J.C. VanderKam and P.W. Flint (Leiden: Brill , 1999), vol. 2, 213-278. 
Esta misma función sacerdotal de los ángeles, es más directa en los libros de los Jubileos 30:18 (no presente en Qumrán) donde ángeles de Dios declaran: “La simiente de Leví fue escogida para el sacerdocio y para [las órdenes] levíticas a fin de ministrar siempre delante del Señor tal cual nosotros lo hacemos". El documento también habla de los "ángeles de la presencia" que se encuentran delante del Señor. "ministrando en su santuario" (Jub 31:14) y son descritos como modelos para los levitas. Así el texto trata de ciertas órdenes angélicas como realizando un tipo de función sacerdotal en el santuario del cielo. ${ }^{39}$

Tal ministerio se torna especialmente intrigante si consideramos que para los cristianos el ejercicio sacerdotal está más ligado a la persona de Jesucristo, el único mediador entre Dios y los hombres ( 1 Tim 2:5 cf. Heb 4:14-16; 8:1-6). Sin embargo, el propio Newsom admite que aun cuando la angelología judaica esporádicamente presente ángeles en funciones sacerdotales, el término kōhen nunca es aplicado directamente a ellos, ni aquí ni en ningún otro manuscrito del Qumrán, ni aun en la literatura rabínica u apócrifa. ${ }^{40}$ Entretanto, el 4Q400 [4QShirShab ${ }^{a}$ ] habla de seres celestiales (que se identifican con los ángeles o por lo menos los incluyen) que tienen acceso privilegiado al trono de Dios y por eso son llamados "sacerdotes del lugar santísimo" (coheni qworb 4Q400 1 I 817 19; 4Q403 1 II 19 24;

${ }^{39}$ Fletcher-Louis defiende una hipótesis de que esa clase angelical puede referirse a seres humanos redimidos que se divinizan o se "angelicalizan" a través de la adoración como si estuviesen en el cielo fungiendo como sacerdotes delante de Dios. Sin embargo, pocos se adhieren a su interpretación. C. H. T. Fletcher-Louis, All the Glory of Adam: Liturgical Anthropology in the Dead Sea Scrolls, Studies on the Texts of the Desert of Judah 42 (Leiden: Brill, 2002).

${ }^{40}$ Newsom, Songs of the Sabbath Sacrifice: A Critical Edition, 26 
4Q405 211) o también "los espíritus del lugar santísimo" (ruachi qwrb 4Q405 frag. 14-15, I 4). ${ }^{41}$ Ellos se aproximan al trono con acciones de gracia y ofrecimiento de expiación por los pecadores penitentes. Pero ¿qué pasa con el sacerdocio exclusivo del Mesías?

En primer lugar, se debe recordar que, aun en el Nuevo Testamento, la promesa de sacerdocio real es extendida también a seres humanos en la tierra y en el cielo (1 Ped 2:5-9; Apo 1:5-6; 5:10; 20:6). Tales funciones sacerdotales, según el Apocalipsis, también son ejercidas por ángeles en el santuario celestial (Apo 8:3; 15:6-8). Pero se debe notar que realmente se trata de un "subsacerdocio" inferior, funcionalmente auxiliar. Pues no tiene el carácter intercesor y meritorio que es exclusivo del ministerio de Cristo, llamado correctamente de "Sumo Sacerdote" en el libro de Hebreos 2:17; 4:14.

De hecho, existe una jerarquía angélica y sacerdotal en los cánticos del Qumrán. Estos seres o adoradores celestiales son divididos en órdenes aparentemente jerárquicas: ángeles, elim, elohim, querubín, ophanim ${ }^{42}$ espíritus vivientes, jefes (príncipes), sacerdotes, ministros, santos y dignatarios.

Durante el curso litúrgico de los 13 sábados, aparentemente nuevas canciones deberían ser recitadas por diferentes grupos de adoradores. Quien hace esta afirmación es Bilha Nitzan, en su estudio: "la idea de la santidad en

${ }^{41}$ Esta es la forma como $Q R B$ es grabada en los Manuscritos de Qumrán. Cf. E. Qimron, The Hebrew of the Dead Sea Scrolls (Atlanta GE: Scholars Press, 1986), 65. 1:15-21.

${ }^{42}$ Ophanim se refiere a las ruedas celestiales de la visión de Ezequiel 
la liturgia y en la poesía del Qumrán" ${ }^{43}$ Ella entiende que para la comunidad, aquel rito representaba la elevación gradual de la alabanza de los adoradores terrestres de la comunidad, que se elevaba a través del coro de ángeles, los ángeles sacerdotes, los carruajes, los querubines, las ruedas ubicadas debajo del trono celestial hasta llegar a las canciones de la actividad sumo sacerdotal ministrada en el devir, es decir en el santo de los santos, delante del trono de Dios. Únicamente en el décimo tercer sábado, esa alabanza llegaba al mismo altar celestial. Solamente allí realmente la expiación era consumada (11Q 17 [11QShirShab] 7-8).

\section{Sacerdocio mesiánico}

En el texto de los Canticos es notoria la idea de que había un ángel superior presidiendo el trabajo sacerdotal de las demás huestes. El uso del singular nšy' (líder) en 4Q401 231 y šr (príncipe) en 4Q403 1 II 23, sugiere la existencia de este ser celestial. También el texto de 4Q403 1 II 24 presenta la frase "cabeza de los sacerdotes en el lugar santísimo (rwsh mkwhn qwrb), lo que implica que un ser celestial ejerce autoridad sobre los demás ángeles que actúan en el santo de los santos.

¿Quién puede ser ese ser? Dos figuras intercambiables y no excluyentes aparecen como respuesta: Miguel y Melquisedec. Varios autores llegan a esa conclusión. ${ }^{44}$ De

${ }^{43}$ B. Nitzan "The idea of holiness in Qumrán poetry and liturgy" en Sapiential, Liturgical and Poetical Texts from Qumran, eds. E G. Martinez and E. M. Schuller (Leiden: Brill. 2000), 143. Cf. también, Newsom, Songs of the Sabbath Sacrifice: A Critical Edition, 371-372.

${ }^{44}$ Cf. P. J. Kobelski, “Melchizedek and Mechiresa” (CBQMS 10) (Washington: The Catholic Biblical Association of America, 1981) 1-23; G. 
hecho, aun cuando en los Cánticos el nombre de Miguel jamás aparezca, en el Manuscrito de la Guerra (1Q33 13 10; 16 6-8; 17 7) él, es llamado "príncipe de la luz" (1Q33 13 10-11) e identificado con Melquisedec, el rey y sacerdote.

Comenzando pues, por Melquisedec, tenemos aquí la referencia a un misterioso individuo mencionado primeramente en Gen 14:18-20, a quién Abraham trató como verdadero sacerdote del altísimo. Después él reaparece en el Sal 110:4, dentro de un contexto claramente mesiánico. Fuera de estos textos veterotestamentarios, se sabe muy poco sobre él, la teología formada entorno a su persona, viene especialmente del libro de Hebreos, que lo torna un tipo de Cristo y de su ministerio sacerdotal delante de Dios.

En el caso de los Cánticos las dos posibles referencias a él como el jefe de los sacerdotes angelicales son fragmentarias, y aun cuando posible, no puede ser concluyente: 4Q401 113 dice "[Melqui]sedec sacerdote en la asamblea de Dios" ([mlky]tsadq kwhn) y 4Q401 223 presenta el término "[Mel]qui sedec" en una línea que sigue a una referencia sobre la ordenación de los ángeles para el sacerdocio.

Newson reconstruyó las oraciones de, por lo menos, 38 diferentes fragmentos y decidió que la unión de algunas de ellas podría formar la palabra Melquisedec. ${ }^{45}$ Ella también se valió de un texto encontrado en 11Q13 (11QMelquisedec) que en su opinión es paralelo al texto de 4Q401 y que puede ayudar a su restauración.

Vermes, The Complete Dead Sea Scrolls in English, ed. rev. (Harmondsworth, UK: Penguin Books, 2004), 532-534; M. Wise, M. Abegg, E. Cook, The Dead Sea Scrolls: A New Translation (San Francisco: Harper Collins, 1996), 455; Carol Newsom, Songs of the Sabbath Sacrifice: A Critical Edition, 37.

${ }^{45}$ Newsom, Songs of the Sabbath Sacrifice: A Critical Edition, 37-38, 78. 
El texto de 11Q13 II 4b-18 habla de la expiación hecha por los hijos de Dios y trata a Melquisedec al mismo tiempo como ángel guerrero, ser celestial y Dios (elohim). ${ }^{46}$ Aun cuando este título (elohim) también se use para referirse de forma colectiva a otros ángeles, aquí llama la atención el que se lo aplique de forma singular a un único individuo. Eso es inédito.

Dice el texto:

“'Para proclamar a los cautivos la liberación'. Y hará prisioneros a sus rebeldes [...] y de la herencia de Melquisedec, pues [...] y ellos serán la herencia de Melquisedec, que los hará retornar a ellos. Él les proclamará la liberación para liberarlos de [la deuda] de todas sus iniquidades. Y esto suce[derá] en la primera semana del jubileo que sigue a los nue[ve] jubileos. $Y$ el día de las expiacio[nes] es el final del décimo jubileo en el cual se hará expiación por todos los hijos de [Dios] y por los hombres de la herencia de Melquisedec. [Y en las alturas] él se pronun[ciará a su] favor de acuerdo a sus cualidades pues es el tiempo del 'año de la gracia' para Melquisedec, para exal[tar en el pro]ceso a los santos de Dios (...) como está escrito acerca de él en los cánticos de David donde dice 'Elohim se levanta en la asam[blea de Dios], entre los dioses juzga'. Y sobre él dice 'sobre ella retorna a las alturas, Dios juzgará los pue-

${ }^{46}$ J. R. Davila, Liturgical Works, Eerdmans Commentaries on the Dead Sea. Scrolls 6 (Grand Rapids, MI: Eerdmans 2000), 165. 
blos' (...) Sin embargo Melquisedec ejecutará la venganza de los juicios de Dios, y él pre[sidirá la asamblea] (...) el pregonero es [el ún]gido del espíritu del cual habló $\mathrm{Da}[$ niel] (...) y el pregonero [del] bien que anuncia la salva[ción] es aquel del cual está escrito que [él] lo enviará para 'consolar a los afligidos'".

Es imposible no hacer una relación entre lo mencionado en Isa 61:1-2 como cumpliéndose en Melquisedec y Luc 4:17-21 donde Jesús afirma que esto se cumplió en él. También es notorio en el texto qumránico la divinidad de este sujeto, su trabajo de expiación/salvación y su preminencia sobre los ángeles y sobre los elim. Note que el autor cita el Sal 82:1 ("Dios está en la reunión de los dioses; En medio de los dioses juzga"), y en un principio se atribuyen a él estas palabras, luego cita una segunda vez el mismo pasaje, pero substituye el término "Dios" (elohim) por Melquisedec. El texto claramente presenta a un misterioso personaje, representado en el rey-sacerdote de Salem, que se ubica en el lugar de Dios durante el juicio final del universo.

Filón también relaciona a Melquisedec con el logos divino (aun cuando lo trata como a un demiurgo). Para él Melquisedec es "el logos, el sacerdote cuyo linaje es el verdadero Dios" (De Allegoriis Legum III, 26) ${ }^{47} \mathrm{Y}$ no se puede olvidar la ya mencionada correlación que el libro de Hebreos hace entre esa enigmática figura y el ministerio sacerdotal del Cristo en el cielo. ${ }^{48}$

\footnotetext{
47Jewish Encyclopedia Online, s.v. "Melchizedek", http://www. jewishencyclopedia.com/articles/10602-melchizedek (consultado: 4 de Febrero, 2013).
}

${ }^{48} \mathrm{En}$ su tesis doctoral sobre esa colección de cánticos, Jared C. 
Hay otro importante elemento a lo largo de 11QMelquisedeque (11Q13) que también merece ser mencionado: el trabajo sacerdotal y expiatorio de Melquisedec se realiza en el día de la expiación, por lo tanto, él es un sumo sacerdote. En el cierre del texto, ese día es relacionado al juicio final en el que "Melquisedec librará [los hijos de la justicia] de las manos de Belial" (11Q13 II 25).

Aun cuando estos textos del Qumrán no mencionen a Miguel, es posible ver una semejanza entre el personaje principal y la acción del arcángel mencionado en Daniel 12:1. Despues de todo, otros textos especialmente el Manuscrito de la Guerra (1 Q33 13 10-11; 17 5-6 etc.) muestran la misma batalla final entre Belial y sus aliados contra los hijos de la luz - un espacio muy semejante al de 11Q 13 II 25. Sin embargo, en este pasaje, quien auxilia a los hijos de la luz no es Melquisedec sino Miguel. El paralelismo es bastante evidente.

Calaway descubrió una relación interesante entre las canciones sabáticas de Qumrán, la teología del libro de Hebreos y la realidad del Santuario Celestial. En varias ocasiones el autor concluye que "[la]s Canciones del Sacrificio del Sábado y la epístola a los Hebreos reposan sobre las más antiguas articulaciones que reconfiguran la intersección del sábado y del santuario en el ambiente celestial, haciendo del sábado el acceso temporal al santuario celestial y tornando a una expresión equivalente a la felicidad celestial de Dios. Esta intersección del Sábado y del Santuario hace de el una completa expresión de la santidad de Dios en el tiempo y en el espacio, y así, ambos fueron los indicadores primariamente espaciales y temporales de la santidad de Dios y su presencia celestial". J. C. Calaway, "Heavenly Sabbath, Heavenly Sanctuary: The Transformation of Priestly Sacred Space and Sacred Time in the Songs ofthe Sabbath Sacrifice and the Epistle to the Hebrews" (Tesis doctoral, Columbia University, 2010). Otro interesante trabajo de comparaciones entre Hebreos y los Cánticos Sabáticos se encuentra en el artículo de Takaaki Haraguchi " Hebrews 1-2 in the Light of Songs of the Sabbath Sacrifice", Theological Forum 46 (2006), bajo http://yonshin.yonsei.ac.kr/data/\%B D\%C5\%C7\%D0\%B3\%ED\%B4\%DC46-4.pdf. 
Dávila ${ }^{49}$ encontró otra posible referencia a Melquisedec en 4Q401 223 -aun cuando Newson se muestre reticente respecto a esta lectura. Para él allí se está hablando de la batalla en el cielo (comp. Apo 12:7-12) y trae a colación el pasaje del octavo cántico que, en base a otro fragmento, puede ser leído como "los jefes de los príncipes del poderoso sacerdocio de Melquisedec" ${ }^{150}$ - una referencia a los sacerdotes que sirven en el santuario celestial de acuerdo con la orden de Melquisedec (cf. Sal 110:4).

En la Biblia hebrea, Melquisedec claramente es un rey y sacerdote humano de la ciudad de Salém (Gen 14), pero si esas reconstrucciones estuviesen en lo correcto, en Qumrán él pasa a ser un tipo de un sumo sacerdocio superior, que es al mismo tiempo humano, angelical y divino, que además ministra como Dios en el santuario celestial. Además de acuerdo con los manuscritos, Melquisedec/ Miguel es quien proclamará el "día de la expiación" y él hará expiación por su pueblo. Él también juzgará a las naciones.

Paul Rainbown, aun cuando esté en desacuerdo sobre el carácter angelical de Melquisedec en 11QMelquisedec, argumenta que él está por encima de cualquier cosa, una figura mesiánica, descendiente del linaje de David. ${ }^{51}$ Aun cuando no estemos de acuerdo con el "origen mitológico" de los personajes, como es propuesto por Dávila y con algunas conclusiones a la que él llega, se cree que su lectura de los textos del Qumrán fue más completa y

${ }^{49}$ Davila, Liturgical Works, 162-163.

${ }^{50}$ Ibíd., 132 -133.

${ }^{51}$ Para su argumentación véase $\mathrm{P}$. Rainbown, "Melchizedek as a Messiah at Qumran", Bulletin for Biblical Research 7 (1997) 179-194. 
comparativa que la de Rainbown. Para él, si juntáramos todos los textos relacionados al tema es posible deducir que para los miembros de la comunidad Miguel sería el primer protagonista angelical que substituye a Yahweh en la teología judaica, teniendo a Melquisedec - la figura sacerdotal divinizada - como su equivalente literario en algunas versiones. Jesús, claramente sería la figura correspondiente en el Nuevo Testamento. ${ }^{52}$

\section{Santuario e historia}

Volviendo a hablar específicamente de los Cánticos, una de las más importantes conclusiones de Newsom es que estos himnos no idealizan ningún lugar imaginario, sino que tratan al ambiente del templo celestial como un ambiente real en el plano superior. Lo que ocurre allí está interconectado a lo que pasa en el plano terrestre. ${ }^{53}$ En otras palabras, lo que acontece en el santuario celestial se refleja en la historia terrestre y viceversa.

En resumen: para los miembros de la comunidad, el ministerio realizado en el cielo tenía íntima relación con los

${ }^{52}$ J. R. Dávila, "Melchizedek, Michael, and War in Heaven”, Society of Biblical Literature Seminar Papers 35 (Atlanta, GA: Scholars Press, 1996), 259-272. Otras argumentaciones y paralelos de Dávila están en James Dávila, "Melchizedek, the Youth and Jesus", en The Dead Sea Scrolls as Background to Parabiblical Judaism and Early Christianity, ed., James Dávila (Leiden: Brill 2003), 248-274. Cf. también J. A. Fitzmeyer, "Further Light on Melchizedek from Qumran Cave II", Journal of Biblical Literature 86 (1967), 25-41

${ }^{53}$ Newsom, Songs of the Sabbath Sacrifice: A Critical Edition, 64. Para una interpretación diferente de Newsom que niega esa visión dualista del cielo/tierra y ve seres humanos como posibles miembros de esta liturgia celestial véase C. H. T. Fletcher-Louis All the Glory of Adam: Liturgical Anthropology en the Dead Sea Scrolls, StdJ 42 (leiden: Brill, 2002), 256, 257. 
tiempos en los que ellos vivían. Ese tiempo era conocido como la "edad impía" y era dominado por el "sacerdote impío", el enemigo voraz de los seguidores del Maestro de Justicia (Moreh-Ha-Tzadik) que para muchos podría ser el mesías esperado por la comunidad (1QpHab 11 4-6). ${ }^{54}$

El mundo por lo tanto, estaba dividido entre los seguidores del Maestro de Justicia y los seguidores del Sacerdote impío. La diferencia entre estos grupos radicaba en que el primero seguía la verdadera ley de Dios, mientras que los demás seguían la ley falsa, siendo llamados debido a ello de "buscadores de cosas suaves" (4Q169 3-4; I 2 7; II 2 4; III 3 6-7). El Maestro de Justicia y el Sacerdote surgirían para revelar la verdadera ley de Dios e interpretar la Palabra dada a los siervos, los profetas (4QpHab 1 $11 ; 28-11)$.

Es por causa de este conflicto entre la verdad y el error que la comunidad se veía exiliada en el desierto - como la mujer de Apocalipsis 12. En su tipología, ellos creían estar insertados en un período de exilio profético en el desierto reservado para el remanente justo, es decir, para aquellos que cumplían la verdadera ley de Dios (moral, civil, ceremonial y de purificación) en contraste con las falsas leyes

${ }^{54}$ Este no es un punto harmonioso entre los académicos. F. B. Bruce, por ejemplo, entendía que él no sería el Mesías, mas un precursor de él. Véase F. B. Bruce, "The Teacher of Righteousness in the Qumran Texts" (Investigación presentada en The Tyndale Lecture in Biblical Archaeology, London, 6 de julio, 1956). Consultado en bajo http://www.biblicalstudies.org.uk/pdf/qumran_bruce. pdf); Kerry A. Shirts entiende que existe alta probabilidad de ser una figura Mesiánica, Sin embargo evita cualquier dogmatismo a este respecto. véase K. A. Shirts, "Who Was the Teacher of Righteousness in the Dead Sea Scrolls" bajo http://www2.ida.net/graphics/shirtail/deadsea.htm (Consultado: 3 de abril, 2013). Con todo, gran parte de los académicos todavía siguen (con variaciones de argumento) la linea que ve en el Maestro de Justicia una figura mesiánica aguardada por la comunidad. 
instituidas en el santuario de Jerusalén. Las verdaderas prescripciones estarían en cualquier documento del rollo del Templo (11Q19 e 11Q20). ${ }^{55}$

La controversia haláquica aún les llevaba a negar la versión de la ley expuesta por el llamado sacerdote impío. Que actuaba en el santuario de Dios, profanándolo con su enseñanza y comportamiento. F. M. Cross observó que él no solo profanaba el santuario sino que también alteraba las leyes y los tiempos ceremoniales, un paralelo interesante con el poder denunciado en Daniel 7:25. ${ }^{56}$

Pero al final de este período o de esta "edad impía", los justos recibirían la tierra así como las generaciones nacidas en el desierto recibirían Canaán. Su salida del desierto coincidiría con el inicio del "fin de los días", un tiempo aún futuro en el que el Maestro de Justicia se levantaría e iniciaría el Eschaton y el fin de la falsa ley y de la era de iniquidades en el santuario.

\section{Unión entre el cielo y la tierra}

Ciertas veces, especialmente en el repertorio de los Cánticos Sabáticos (6-8), los seres y las órdenes celestiales son invitadas a adorar junto con los hombres. En otras los hombres que participan de la adoración celestial (4Q400

${ }^{55}$ L. H. Schiffman, The Halakhah at Qumran, Studies in Judaism in Late Antiquity 16 (Leiden: Brill, 1975), esp. 75-76; N. Nacham, “Exile And Self-Identity In The Qumrán Sect And In Hellenistic Judaism" en New Perspectives on Old Texts; Proceedings of the Tenth International Symposium of the Orion Center for the Study of the Dead Sea Scrolls and Associated Literature, 9-11 January, 2005, eds., E. G. Chazon, B. Halpern-Amaru, R. A. Clements (Leiden: Brill, 2010), 3-21.

${ }^{56}$ F. M. Cross, The Ancient Library of Qumran, (Sheffield: Sheffield Academic Press, 1995), 128-129. 
21-3 8). En otras partes, aún los seres celestiales son descritos como ejecutando una liturgia superior de la cual no somos dignos ni de contemplar. "Y en todas las excelsas alturas [cantarán] salmos maravillosos según todo [su conocimiento] y contarán [el esplendor] de la gloria del rey de los dioses en las moradas de sus posiciones. Vacat. Y [...] ¿cómo será considerado entre ello? Y nuestro sacerdocio (¿Cómo será considerado) en sus residencias? [...] ¿Qué es la ofrenda de nuestra lengua de polvo, (comparada) con el conocimiento de los divinos?" 4Q400 2, 5-7.

A pesar de todo, la Regla de las Bendiciones (1Q28b III 24-27) se hace eco de la esperanza del día en el que los “hijos de Sadoc, los sacerdotes que Dios escogió para sí para reforzar su alianza para siempre" irán a vivir "como ornamento glorioso en medio de los santos" (¿ángeles?) "en la morada santa" como renovación del "pacto del sacerdocio eterno" (com. Sal 110:4 y Heb 5:6; 7:17).

Si bien esa esperanza escatológica no se concretiza, Newsom cree que la comunidad de Qumrán se consideraba un Ersatz, templo espiritual e interino en la tierra que substituía con sus oraciones y liturgias el sacrificio corrupto del Tempo de Jerusalén. Sin embargo, para ellos, la comunidad y la ceremonia celestial eran superiores y más completas que el formalismo ceremonial terrenal. ${ }^{57}$

${ }^{57} \mathrm{La}$ mayor parte de los autores piensan así, con todo Schwartz cree que la sinagoga local más que la comunidad ejercería ese papel. D. R. Schwartz, "Temple and Desert: On Religion and State in Judaea of the Second Temple Period, Priesthood and Monarchy" en Studies in the Jewish Background of Christianity [Wissenschaftliche Untersuchungen zum Neuen Testament, vol. 60] (Tübingen: Mohr Siebeck, 1992), 38. 
¿Sería ese un indicio de que ellos no realizaban sacrificios en los que se veía involucrado el derramamiento de sangre? Es difícil dar una respuesta concluyente, sin embargo ella parece ser "Si". Es verdad que los himnos inician con el prólogo: "[Para el instructor. Cántico para el holocausto] del primer [sábado]..." (4Q400 1 I 1) y así sucesivamente. Pero según todos los indicios, se trataba de algún tiempo de sacrificio espiritual realizado "en el cielo". ${ }^{58} \mathrm{Al}$ parecer ellos no sacrificaban animales, considerando especialmente que estos remitían al servicio diario del templo de Jerusalén que estaba corrupto.

Los textos afirman que los miembros de la comunidad rechazaron los sacrificios de expiación hechos en el templo de Jerusalén y, por lo menos temporalmente, substituyeron su participación en estos sacrificios por oraciones y actos de justicia. ${ }^{59}$

Era justamente la corrupción del Templo la que contaminaba el santuario, haciendo con que el ritual de expiación fuese transferido para el cielo y representado en la tierra por la liturgia de la comunidad. Los textos, sin embargo, no ofrecen detalles de cómo este sacrificio era hecho en las cortes celestiales.

Para Gärtner, los miembros de Qumrán entendían el sacrificio diario como parte de un prolongado "acto de ex-

${ }^{58}$ H. W. M. Rietz, "Identifying Compositions and Traditions of the Qumrán Community, 42, 43; John Maier, "Shire olat hash-Shabbat: Some Observations on their Calendric Implication and on their Style", en The Madrid Qumran Congress: Studies on the Texts of the Desert of Judea, eds., J. T. Barrera e L. V. Montaner (Leiden: Brill,1992), vol. 2, 542-560.

${ }^{59}$ C. L. Quarles, “The New Perspective and Means of Atonement in Jewish Literature of the Second Temple Period", Criswell Theological Review 2 (2005) 54; Maier, "Shire olat hash-Shabbat", 553. 
piación" mayor que el simple degollamiento de corderos. De este modo, ello podía ser cambiado por acciones de gracia y una vida de rectitud. ${ }^{60}$

De hecho, textos como 1QS 9 3-5, donde el pecador puede aparentemente conseguir su perdón "sin la carne de holocausto y sin la grasa del sacrificio" apuntan en esta dirección. Esto, sumado al hecho de que ningún altar o hueso de animales sacrificados fueron encontrados en las excavaciones del sitio, aumentan exponencialmente la probabilidad de que los miembros del Qunram no participaban literalmente en ninguna forma de sacrificio relacionado con el degollamiento y quema de corderos como ofrenda al Señor.

Nitzan, también aboga sobre las canciones sabáticas diciendo que ellas eran un substituto litúrgico del sacrificio. ${ }^{61}$ Ella señala como evidencia de ello, frases del tipo: "los jefes de las ofrendas de alabanza son las lenguas del conocimiento. Ellos bendicen al Dios del conocimiento en todas las obras de su gloria" (4Q405 23 II 12); "la ofrenda de sus lenguas" (4Q403 1 II 26) y "ofrenda de nuestra lengua de polvo" (4Q400 2 7). En su opinión, este lenguaje evidencia la correlación entre sacrificio y cánticos litúrgicos. Pero también recuerda que, aun cuando para ella los cánticos podrían ser recitados en el sábado a la hora del sacrificio, los himnos tenían por objetivo una unión mística con el cielo y no una liturgia estrictamente definida.

${ }^{60} \mathrm{~B}$. E. Gärtner, The Temple and the Community in Qumran and the New Testament: A Comparative Study in the Temple Symbolism of the Qumran Texts and the New Testament, Society for New Testament, Studies Monograph Series 1 (Cambridge: Cambridge University, 1965), 87.

${ }^{61}$ B. Nitzan, Qumran Prayer and Religious Poetry, Studies on the Texts of the Desert of Judea 12 (Leiden: E.J. Brill, 1994), 282, 290-291. 
Siendo así, otra pregunta se hace necesaria: ¿Qué tipo de expiación era esperada en el ministerio celestial? De acuerdo a varias partes tanto del Qumrán como de la antigua literatura judía, el sacrifico ofrecido por los ángeles no implicaba un derramamiento de sangre en el cielo. Su función se resumía en pedir a Dios que perdonase el pecado de sus hijos. ${ }^{62}$

Pero esa no era una situación ideal. La expiación todavía debía ser hecha. Siendo así, la comunidad nutría la esperanza de una futura venida del Mesías para ejecutar la expiación divina. Como concluye Garnet, los miembros de Qumrán no abandonaron el culto del sacrificio expiatorio, sino que sólo lo postergaron para el futuro, para el día cuando el Mesías realizaría personalmente esa tarea sacerdotal. ${ }^{63}$

\section{Expiación Mesiánica}

Los sacrificios comunitarios, por lo tanto, eran una forma provisoria de expiación litúrgica donde los miembros, a través del arrepentimiento (individual y colectivo) y de las acciones piadosas o "actos de expiación [kippurim]", se preparaban para la venida del Mesías, el único que (juntamente con Dios) podría, en última instancia, expiar de una vez por toda la culpa

${ }^{62}$ Esto puede ser visto en I Enoc, Tobias, Baruq Griego, Apocalipsis de Sofonias etc. En el Testamento de Levi 3. Cf. F. G. Martinez, Echoes From the Caves Qumran and the New Testament, Studies on the Texts of the Desert of Judah 85 (Leiden: Brill, 2009), 168.

${ }^{63} \mathrm{P}$. Garnet, Salvation and Atonement in the Qumran Scrolls, Wissenschaftliche Untersuchungen zum Neuen Testament 2 (Tubingen: J. C. B. Mohr, 1977), 101. 
humana (1QS 2 26-3 4; 3 10; cf. también 1QS 5 6; 8 3-6; $94) \cdot{ }^{64}$

Dice un trecho del Documento de Damasco: "Y esta es la exacta interpretación de las normas por las cuales [se regirán] [hasta que aparezca el Mesías] de Arón y de Israel. Él expiará por sus pecados [... el perdón, y la culpa]" (4Q271 13 1b-3 [CD A XIV, 18-22]). Otro texto que afirma esto, aunque no indica directamente el sujeto de la expiación, es el Testamento de Levi que dice “... y él pasará sobre [para ellos (su hijo) su s[abiduría] Él expiará por todos los hijos de su generación y será enviado para todos los hijos de su [pue]blo. Su palabra es como una palabra del cielo. Y su enseñanza está de acuerdo con la voluntad de Dios. Su sol eterno brillará y su fuego quemará en todos los confines de la tierra" (4Q541 9 I 1-3).

Lo que se encuentra, sin embargo, es una referencia inequívoca de que el Mesías expiaría la culpa por medio de su sangre. Las indicaciones sobre eso son fragmentarias, inconclusas y plausibles de discusión. ${ }^{65}$ En algunos textos el Mesías parece hasta distinto y sujeto a la acción de los sacerdotes. En la hora del refrigerio ritual futuro, él entra después del Sacerdote jefe y demás sacerdotes y solamente ahí asume su lugar en la mesa (1Q28a 2 I 1-22).

${ }^{64}$ Ibid., 99.

${ }^{65}$ Vea por ejemplo las intentos de William H. Brownlee y Dominique Barthélemy de encontrar en Qumrán una evidencia literaria para la expiación traída a partir de la muerte del Mesías: W.H. Brownlee, "The Cross of Christ in the Light of Ancient Scrolls", The United Presbyterian 28 (1953) 10-11; idem, "The Servant of the Lord in the Qumran Scrolls", Bulletin of the American Schools of Oriental Research 132 (1953) 8-15; idem, "Messianic Motifs of Qumran and the New Testament", New Testament Studies 3 (1956-57) 12-30, 195-210; D. Barthélemy, “Le grand rouleau d'Isaie trouvé près de la Mer Morte", Revue Biblique 57 (1950) 530-49 (546-49). 
Más aún, él es instruido por los sacerdotes y aprende de ellos (4Q161 9-9 III, 11-25). Nuevamente, aunque no sea una deducción conclusiva, es posible ver aquí una actitud de sumisión mesiánica que es como un eco cercano a la expresión "como oveja delante de sus trasquiladores, enmudeció, y no abrió su boca" (Isa 53:7).

No obstante la ausencia de una "muerte expiatoria" hay señales claras de que, juntamente con la expiación final y como consecuencia de ella, viene el sufrimiento mesiánico. Siguiendo la descripción de su obra expiatoria, el Testamento de Levi complementa ello diciendo: “Declararán contra él muchas palabras, y abundancia de mentiras; investigarán fábulas contra él, y dirán toda suerte de infamias contra él. Su generación transformará el mal, y [...] establecida en la mentira y en la violencia. El pueblo errará en sus días y estarán confusos" (4Q541 9 I 2b-7).

Otro trecho que merece ser considerado es el Himno de la Auto-glorificación, publicado por Esther Eshel ${ }^{66} \mathrm{y}$ reinterpretado recientemente por Israel Knohl. ${ }^{67}$ Se trata de una composición recuperada a partir de varios testigos textuales 4Q471b, 4Q491, 4Q427 y, quizá, 4Q43. Su poema parece hablar del sufrimiento de un Mesías al mismo tiempo divino y humano. Es un lamento en primera persona basado en Isaías 53:

"[vacat Yo soy] cont[ado] entre los angeles mi habitación en el santo [concilio]

${ }^{66}$ E. Eshel, "4Q471b: A Self-Glorification Hymn", Revue de Qumrán 17 (1996) 186-94.

${ }^{67}$ I. Knohl, The Messiah Before Jesus - the Suffering Servant of the Dead Sea Scrolls (Oakland, Ca: Regents of the University of California, 2000). 
¿Quién ha sido despreciado como [yo?

Y ¿quién] ha sido rechazado [por los hombres]

como yo?

Y ¿quién se comparará a mí en tolerar (soportar) el mal?

[ninguna enseñanza] se compara a mi enseñanza. [Pues] estoy sentado [... en el cielo]

¿Quién es como yo entre los ángeles?

[Yo] soy el amado del rey, la compañía de los san[tos] (4Q431 e 4Q427 7)". ${ }^{68}$

En otra sección de este mismo himno, el narrador tiene la experiencia de sentarse en un trono en el cielo, ser contado entre los ángeles, tener un deseo que no viene de la carne y finalmente ser el más glorificado.

"Mi gloria es incomparable y fuera de mi nadie es exaltado. $\mathrm{Y}$ no vengan a mi, porque yo vivo en $[. .$.$] en los cielos, y no hay [...]$

Soy contado entre los ángeles [elim] y mi lugar es en el santo [monte] de la congregación. [Mi] deseo no es conforme a la carne [...] todo lo que es precioso para mí está en mi gloria.

... ¿Quién es comparado a mí en mi gloria?" (4Q491 11 I 13-15).

En otro himno de esa misma colección se lee:

“Alégrense ustedes, justos entre los ángeles

${ }^{68}$ Reconstrucción sugerida por Eshel (DJD 29.428) y citada por Knhol, 86. 
[...] en la santa morada, entonen[-le] himnos

[...anun]cien el sonido de un alarido [...] en eterno júbilo, sim [...]

[...] para establecer la trompeta de [su] Mes[ías]

$[\ldots]$ para dar a conocer su fuerza en poder $[\ldots]]^{\prime \prime}$

(4Q491 $11 \mathrm{I})$

No solo es notoria la semejanza con Isa 53, como también la dicotomía entre un Mesías que sufre para después ser glorificado. El texto aún habla de alguien sin un ser análogo entre los hombres. La combinación especial de estatus divino y sufrimiento humano en una sola persona es algo inédito en la literatura judía más antigua. Es notoria la comparación entre la retórica “¿Quién es como yo entre los ángeles [lit. elim]?" y el texto de Éxodo 15:11 “¿Quién como tú, oh Jehová, entre los dioses? [elim]?"

Recientemente Eric Miller sugirió que el narrador de este poema sería Enoc glorificado. ${ }^{69}$ Pero esa no parece ser una identificación consistente con todos los aspectos del texto en el que el narrador se presenta al mismo tiempo divino y humano. En base a esta condición de agente divino, Maurice Baillet, llegó a sugerir que el narrado no podría ser humano. Para él se trata del arcángel Miguel. ${ }^{70}$ Morton Smith, por su parte, objetó a Baillet, argumentando que la figura del texto sería un ser humano al que se le atribuye un

${ }^{69}$ E. Miller, "The Self-Glorification Hymn Reexamined", Henoch 31 (2009) 307-324.

${ }^{70}$ M. Baillet, Discoveries in the Judean Desert VII, Qumran Grotte, 4, III (4Q482-4Q520) (Oxford: Clarendon Press, 1982), $26-29$. 
estatus angelical (o divino). ${ }^{71}$ Alguien concluye el autor en otra investigación, especialmente equiparado a Jesús. $^{72}$

\section{Purificación del Santuario}

Los textos no traen ninguna alusión directa a Daniel 8:14 o a la "purificación del santuario". ${ }^{73}$ Sin embargo, la temática puede ser encontrada en varios pasajes que proyecta la esperanza en la futura purificación del templo de Dios. Los miembros de la comunidad parecían esperar por el día en que el Santuario Purificado recibiese nuevamente el sacrificio aceptado por Dios. ${ }^{74}$ Finalmente la propia corrupción del Templo demandaba una intervención divina.

El templo de Jerusalén, recordemos, estaba profanado por el "sacerdote impío" y sus "sacerdotes impuros" que "continuamente contaminan el santuario" (CD-A 4

${ }^{71}$ M. Smith, "Ascent to the Heavens and Deification in 4QMa", en Archaeology and History in the Dead Sea Scrolls: The New York University Conference in Memory of Yigael Yadin, ed., Lawrence Shiffman (Sheffield: Journal for the Study of the Pseudepigrapha Supplement Series 8, 1990), 181-188.

${ }^{72} \mathrm{M}$. Smith, "Two Ascended to Heaven-Jesus and the Author of 4Q491", en Jesus and the Dead Sea Scrolls, ed., James H. Charlesworth (New York: Doubleday, ABRL, 1992), 290-301.

${ }^{73} \mathrm{El}$ único manuscrito de la parte de Daniel 8:14 es el 4QDan ${ }^{\mathrm{b}}$ que trae el trecho fragmentado de Daniel 8:13-16. Con todo del verso 14 solo se hallan preservadas dos palabras: wnsdq qwds que los autores modernos correctamente traducen por "el santuario será purificado". E. Ulrich, "Daniel Manuscripts from Qumran. Part 1: A Preliminary Edition of 4QDana", BASOR 268 (1987) 17-37.

${ }^{74} \mathrm{C}$. L. Quarles, "The New Perspective and Means of Atonement in Jewish Literature of the Second Temple Period", Criswell Theological Review 2 (2005) 39-56. 
17; 5 6-11). Esto fue el resultado de una apostasía de las verdades de Dios.

El "sacerdote impío" (hkwhn hrsh') o "sacerdote que se reveló" es una conocida figura que en los Pesharim de Salmos y de Habacuc, es responsable por el daño causado al santuario y a las verdades divinas (4Q171 4 8; 1QpHab 88 16; 9 9; 11 4-5; 122 6). En otras partes de los Pesharim y también del Documento de Damasco él es llamado como el "hombre de burlas" ( $h$ 'sh hltzwn) (CD-A 1 13), "hombre de mentiras" ('sh hkzb) (CD-A 20.15; 1QpHab 2.1b-2a; 5.11; 4Q171 1 26; 4 14), "el derramador de [la] mentira" (mtyp $[h] k z b)$ "aquel que derramó en Israel las aguas de la mentira" (CD-A 8.13; 1QpHab 10.9). Y él es quien adultera y cambia los tiempos (calendario) del Santuario y las leyes de Dios (11Q19 e 11Q20).

De hecho, varios trechos del Pesher de Habacuc muestran que el sacerdote impío inculcaría el desprecio por la ley haciendo que ella caiga en desuso (IQpHab 110 y 11). Y no solamente eso, ellos evidencian una deliberada alteración en los tiempos (por ejemplo en los calendarios litúrgicos) que llevaría al pueblo a una confusión religiosa (1QpHab 8 9-10; 11 2-8 cf. también: 4Q322, 324a-b). ${ }^{75}$

Estas descripciones recuerdan la denuncia paulina sobre una futura apostasía que revelaría al mundo "al hombre de iniquidad", el "hijo de la perdición" (1 Tes 2:3). En la teología de Pablo, ese personaje es el mismo anti-

${ }^{75}$ Más allá de F. M. Cross (mencionado en la nota 55) Este también es el entendimiento de otros autores como J. C. Vanderkam, Calendars in the Dead Sea Scrolls: Measuring Time the Literature of the Dead Sea Scrolls (London: Routledge, 1998), 86, 87; idem, The Dead Sea Scrolls Today (Grand Rapids, MI: Eerdmans, 1994), 130, 131. 
cristo anunciado por Juan (1 Jn 1:18, 19) y simbolizado en Daniel por la imagen de un "cuerno pequeño" que persigue al pueblo de Dios, cambiando los tiempos y la ley y aun ataca al santuario de Dios, contaminando su servicio diario (Dan 7:25; 8:9-14 y 23-25).

En el caso de Daniel, el "cuerno pequeño", aun se levanta contra el Príncipe de los príncipes y su ejército. Ya que el archienemigo denunciado en Qumrán se opone al llamado Maestro de Justicia. Él lo persigue con violencia, así como a sus seguidores, a saber, aquellos que cumplen el pacto (cf. Apo 12:17, 14:12).

El mundo, entonces, en este contexto, es dividido en dos grupos que entablan una batalla espiritual sin tregua y todo ello es conectado con la profanación del santuario y su futura restauración. De un lado están los que siguen al Maestro de Justicia bajo la autoridad de los hijos de Zadoque (el sacerdote que conserva el pacto) y del otro los que hacen alianza con la "congregación del hombre de mentiras" (1QS 5:1).

El rechazo al Maestro de Justicia y a sus enseñanzas es referido en $1 \mathrm{QH}^{\mathrm{a}} 12$ 8-12b.: "Pues en locura realizan sus obras. Porque he sido para ellos objeto de desprecio y no me consideran cuando en mí tú te engrandeces. Pues me expulsan de mi tierra como a un pájaro del nido; todos mis amigos y mis conocidos fueron distanciados de mí y me consideran como un cántaro quebrado. No obstante, ellos son diseminadores de mentiras y videntes de engaño, maquinarán contra mí $\{\ldots\}$ maldades para cambiar tu Ley, que grabaste en mi corazón por enseñanzas halagadoras para tu pueblo; negarán la bebida del conocimiento a los sedientos, en su sede les darán a beber vinagre para que contemplen sus errores. Para que actúen como locos en sus fiestas religiosas". 
La última parte del texto muestra la locura contaminando el templo, al decir que, como resultado del rechazo, los apóstatas actúan como locos en sus festividades religiosas, es decir, en las ceremonias del santuario. Otras denuncias semejantes son hechas en 1QpHab 2 1-3; 109 y 4Q171 1 26-27.

Además, el Señor en persona prometió que luego de la gran apostasía o "de la época de la impiedad" habría una restauración del servicio sacerdotal digno. En otras palabras: una purificación del santuario relacionada con la restauración de la ley y del pacto condicionada por la separación de aquello que es impío.

"La Vara es el intérprete de la ley, de quien Isaías dice: 'Él produce un instrumento para su trabajo' Vacat. Y los nobles del pueblo son los que vinieron para escavar el pozo con las varas que decretó..., para caminar en ellas durante toda la época de la impiedad, y sin las cuales no lo conseguirán, hasta que surga el que enseña la justicia en el final de los tiempos. Vacat. Por eso, todo aquel que se incluya en el pacto, no entrará en el templo para prender en vano su altar. Ellos serán los que cierren la puerta, como dice Dios: '¿Quién entre ustedes cerrará su puerta para que no enciendan mi altar en vano?' a no ser que tenga cuidado de hacer según la exacta interpretación de la ley para la época de la impiedad: para separarse de los hijos del desánimo; para abstenerse de la riqueza impía que contamina, en la promesa o en el voto, y de la riqueza del templo" (CD-A 6 11-16a).

Una corta oración de la comunidad recordará esa esperanza futura cuando la expiación, incluyendo la sangre derramada, confirmaría la purificación del santuario provisto por Dios: “[ ...] Bendito seas, [Dios de Israel] [...] pueblo santo $[\ldots][\ldots]$ el error $[\ldots][\ldots]$ en agua $[\ldots][\ldots]$ 
y bendecirá allí $[\ldots][\ldots]$ delante de ti la fiesta de $[\ldots][\ldots]$ para la purificación [...] [...] y su holocausto. Y bendecirá. Tomará la palabra y dirá: Bendito seas, [Dios de Israel, que] [me perdonaste todas] mis culpas y me purificaste de la indecencia impura / y expiaste/ para que entre [...] la purificación. Y la sangre, el holocausto, de tu benevolencia y la memoria agradable [...] [...] el incienso santo y el perfume agradable a tu buena voluntad" 4Q512 71-17.

Infelizmente el texto está bastante fragmentado y es difícil saber quién es el sujeto de la oración. Sin embargo, es perceptible en esta sección la esperanza de que llegue el día en el que el santuario sería purificado y que una ofrenda de holocausto con sangre derramada por la expiación sería agradable a la buena voluntad de Dios.

La idea es que un día vendría el Mesías y reconstruiría el Templo. Tal realidad implica dos conclusiones. Primero: el templo que sería purificado/restaurado no era el actual Templo de Jerusalén, sino otro aún por venir (11QT 29 7-10). Segundo: ese templo purificado no era terrestre, sino celestial. No es de extrañar que Qumrán haya tenido varias copias en arameo de una descripción de este nuevo templo (5Q15), identificado con la Nueva Jerusalén, descrita en Isaías y definida en Ezequiel 40-46 como un Templo Ideal.

Los textos qumránicos que hablan de la restauración parecen basarse especialmente en Levítico 21:10 y Ezequiel 43:18-27 donde la purificación del templo parece ser el leitmotiv de toda la argumentación. ${ }^{76}$

${ }^{76}$ L. H. Schiffman, "The Milluim Ceremony in the Temple Scroll", New Qumran Texts and Studies, Proceedings of the First Meeting of the International Organization for Qumran Studies, ed. G. J. Brooke (Leiden: E. J. Brill, 1994), 256. 


\section{Purificación y juicio}

¿Cuándo llegaría esa purificación del templo? Qumrán ¿ofrece alguna orientación en ese sentido? La cronología profética de la comunidad es un asunto tan amplio que merecería un estudio específico sobre ello. No obstante, es posible señalar breves e importantes notas sobre su doctrina del santuario: ellos sabían que este sería purificado en un tiempo marcado por Dios y que implicaría la restauración de la verdad.

Comentando sobre el profeta Habacuc, el autor del Pesher que lleva ese nombre, afirmaba que el vidente de Dios no tenía toda la comprensión de su mensaje. Siendo así, la profecía fue parcialmente entendida por el profeta y sus contemporáneos, pero será plenamente entendida en el tiempo del fin: "Dios dice a Habacuc que escriba las cosas que están por venir para la última generación. Pero él no le hizo saber la consumación de la era" ( IQpHab 7:1-2).

Un fragmento del libro de los Jubileos preservado en la cueva 4 ofrece la siguiente información. "Hablo YHWH a [Moisés diciendo: Sube hacia mí] al monte, [y te daré las dos tablas] de piedra. La Tora [y el precepto que escribí para in]stru[ir te. Y subió Moisés al monte de YHWH, y descendió] la gloria de YH[WH] [sobre el monte Sinaí y lo cubrió la nube durante seis días...] [...] [... Y le mostró las di]visiones [de los ti]empos, para la ley [y para el testimonio. Y le dice: Presta atención a todas las pa]labras que yo te digo [en este monte y escríbelas en un libro, para que se]pan sus descendientes que no los abandoné [por todo el mal que hicieron cuando rompieron el pacto que] hoy establezco entre yo y tú [para sus generaciones en el monte Sinaí. Y 
cuando] todas estas cosas vengan sobre ellos [sabrán que fui yo más justo que ellos en todos] sus jui[cios y en todas] sus maldiciones" (4Q216 1 I 5-16).

Note que el texto habla de divisiones del tiempo dadas por Dios. ¿Qué divisiones podrían ser esas? Es difícil saber, pero ciertamente se trataban de períodos proféticos durante los cuales ciertas cosas sobrevendrían al pueblo y una apostasía ocurriría entre ellos, relacionada con la violación de la ley y el "rompimiento del pacto".

En la secuencia del texto (parte que no fue preservada en Qumrán) existen algunas referencias a tablas celestiales donde Dios guarda cuidadosamente el registro de los hechos de los hijos de Israel y los libros celestiales que están constantemente delante del Señor (Jub. 3:22; 5: 12-19; 28:6; 30:22; 36:10 39:6). Sanders llega a suponer que, por lo menos, dos de estos pasajes (3:22; 36.10) se refieren al "libro de la vida" también mencionado en el Nuevo Testamento. ${ }^{77}$

Fragmentos de dos copias de un texto llamado "Periodos de la Creación" fueron encontrados en la cueva 4 y publicados por J. M. Allegro (4Q 180 e 181). Ellos parecen describir la historia de la humanidad comprendida en períodos proféticos que van de la creación hasta el grande Eschaton. Las expresiones, claramente, se delinean en el relato del Génesis, pero asumen un carácter profético donde todo está determinado por la cronología de Dios: "Interpretación sobre los períodos que Dios hizo: un período para completar

${ }^{77}$ Sanders Apud C. L. Quarles, “The New Perspective and Means of Atonement in Jewish Literature of the Second Temple Period", Criswell Theological Review 2 (2005) 41. 
[todo lo que es] y lo que será", "Y eso está grabado en las tablas celestiales", "lo que está es]crito sobre la tierra" etc. (4Q180 1 1, 5-6).

Así, aun cuando no tengamos todas los cálculos proféticos hechos por los miembros de la comunidad de Qumrán, se puede inferir que ellos tenían una visión profético/cronológica de la histórica, y porque no suponer, de la restauración del santuario. La misma referencia que 4Q181 23 hace a la última de las setenta semana de Daniel 9 sugiere que para ellos, la historia estaba realmente dividida en eras, algunas previamente señaladas por la profecía de Dios. Infelizmente la condición fragmentada de los textos no nos permite ir más allá de eso.

Sobre la restauración final de todas las cosas leemos: "'Yo hecho tus cimientos con lápiz [lazuli'] (Isa. 54:11) [su interpretación]: que ellos han fundado el Consejo de la Comunidad, los sacerdotes y el pue[blo] la congregación de sus escogidos, como una piedra de lápiz lazuli en medio de las piedras. [y yo haré como ágata] todos tus pináculos (Isa. 54:12) su interpretación concerniente a los doce [...] iluminación de acuerdo con el juicio del Urim y el Tumim [...sin que] falte ninguno entre ellos, como el sol en toda su luz (Isa 54:12). Y to[das tus puertas de piedras resplandecientes]. Su interpretación se refiere a los jefes de las tribus de Israel en el [fin de los días] de su agrupamiento, sus funciones [...]" (Em 4Q 164 11-8).

Lo que tenemos aquí es una ciudad restaurada cuya descripción recuerda de cerca (además de Isa 54:11, 12) textos como Éxodo 28:17-20 y Ezequiel 48:31-34. La imagen es la misma que aparece en el apocalipsis de Juan respecto a la Nueva Tierra (cap. 21:18-21). Por ser un comentario de Isaías 54 que habla del futuro glorioso de 
Sion y por referirse al fin de los días, no es equivocado entender que se trata de un texto escatológico.

\section{Conclusión}

La reunión de estos textos brevemente analizados demuestra que la creencia en un santuario celestial y sus implicancias para la historia humana fue de suma importancia para algunos segmentos del judaísmo antiguo. Del mismo que los adventistas modernos, aquellos miembros de la comunidad de Qumrán entendieron, basados en su hermenéutica bíblica, que existe un templo divino en el cielo y que la restauración de las verdades divinas está directamente vinculada a él.

Esto muestra, que lejos de haber creado una creencia de forma artificial, los pioneros del adventismo recuperaron puntos religiosos importantes que ya estaban presentes en el mundo judío que recibió al cristianismo.

Las pruebas provistas por los manuscritos del Mar Muerto, claramente van más allá de este trabajo. Muchas otras fuentes antiguas y más recientes podrían ayudar a demostrar de que la creencia en el Santuario celestial fue una enseñanza que se mantuvo a través del tiempo y cuyo origen coincide con la original formación del contexto bíblico. 